\title{
The Local Implementation of a Chronic Disease Management Model for Childhood Overweight and Obesity
}

\author{
Willy J. Brink-Melis a, ${ }^{a} \quad$ Elze R.E. Derksen ${ }^{a, b, c}$ Marjan J. Westerman ${ }^{c}$ \\ Carry M. Renders ${ }^{a, c}$ Jacob C. Seidell ${ }^{a, c}$ Tommy L.S. Visscher ${ }^{a, c}$ \\ a Research Centre for the Prevention of Overweight, VU University Amsterdam / \\ Windesheim University of Applied Sciences, Zwolle, b Icare Youth Health Care, Meppel, \\ 'Institute of Health Sciences, Faculty of Earth and Life Sciences \& EMGO Institute for Health \\ and Care Research, VU University Amsterdam, Amsterdam, the Netherlands
}

\begin{abstract}
Key Words
Childhood obesity $\cdot$ Interdisciplinary $\cdot$ Obesity management $\cdot$ Overweight $\cdot$ Prevention $\cdot$

Primary care $\cdot$ Child $\cdot$ Focus groups $\cdot$ Multi-disciplinary guideline $\cdot$ Parents $\cdot$ Treatment
\end{abstract}

\begin{abstract}
Background: The aim of this study is to determine opportunities and barriers regarding the management of overweight and obese children in daily practice, and to show the value of using focus groups when developing an action plan for childhood overweight management in a local context. Methods: Seven focus groups and four semi-structured interviews were conducted with 29 professionals from nine different care disciplines and 7 parents of overweight and obese children aged 4-19 years. Results: After thorough analysis of the focus groups, issues concerning finding the most appropriate care and realising a long-term weight management in daily practice have become clear. Some examples of these issues are: lack of awareness, reluctance to discuss and refer, mutual cooperation, contradictory advice and expectations of treatment and lack of effective support strategies. Conclusion: Focus groups deliver important information on local issues that are important for the development and implementation of a childhood overweight management action plan. And, besides delivering necessary information, focus groups lead to an increased awareness and willingness to improve childhood overweight management in a local context.
\end{abstract}


Brink-Melis et al.: The Local Implementation of a Chronic Disease Management Model for Childhood Overweight and Obesity

\section{Introduction}

Childhood overweight and obesity have reached epidemic proportions world-wide and in the Netherlands [1, 2]. Besides, the World Health Organisation has declared obesity as a chronic disease [3]. Children with overweight or obesity are at increased risk for multiple medical co-morbidities as well as psychosocial and behavioural problems [4,5]. Furthermore, childhood obesity is a predictor for obesity in adulthood leading to further burden of disease at individual and public health level [6-8]. Determinants to develop overweight and obesity range from environmental to cognitive individual factors $[9,10]$.

European Guidelines and recent developments in the Dutch health care system acknowledge the need for the contribution of various disciplines in a multi-disciplinary setting to prevent chronic diseases [11, 12]. In addition, evaluations that have focused on development and implementation of a chronic management model have shown positive effects on quality of life, clinical outcomes, health care costs and patient satisfaction [1315]. The central aim of integrated care, including targeted prevention, screening, treatment and relapse prevention, is patient-oriented care with a focus on the self-management of patients $[11,12,16,17]$. The implementation of a national chronic disease management model for overweight and obesity is a necessary part to realise integrated care management for overweight and obese children [18].

In The Netherlands, the Youth Health Care (YHC, performed by doctors and nurses) and general practitioners (GPs) are the main health care professionals with regard to prevention and treatment of overweight and obese children. The YHC is facilitated by the government and monitors almost every child (0-19 years) by means of a nation-wide programme at predetermined ages [19]. Growth monitoring is a standard procedure during the health checks, and participation rate is above 95\% [19]. YHC, therefore, has excellent opportunities to detect overweight and to provide a tailored prevention programme. In addition to YHC and GPs there are other health care professionals (e.g. pedagogues, paediatricians, psychologists and dieticians) that play a role in the prevention and treatment of overweight and obesity. Treatment by dieticians is re-imbursed by the regular compulsory health insurance. Treatment by pedagogues and psychologists is not re-imbursed by this compulsory insurance, unless obesity is accompanied by co-morbidities. Although national multi-disciplinary guidelines for overweight and obesity care are gradually becoming available to improve the current care (including targeted prevention, screening and relapse prevention), little is known about the implementation process of these guidelines in a local setting with these different professionals.

The aim of this study is to determine opportunities and barriers regarding the management of overweight and obese children in daily practice, and to show the value of using focus groups when developing an action plan for childhood overweight management in a local context. A qualitative study seems to be the most suitable design for that purpose [20].

\section{Material and Methods}

An explorative, qualitative study has been conducted by carrying out focus groups to gain a better understanding of the opportunities and barriers regarding the local care for children that suffer from overweight or obesity in Zwolle. This city is one of the major cities in the rural North-East of the Netherlands with 117,000 inhabitants. The prevalence of overweight and obesity in children in this region is $10-15 \%$ [21] and is comparable to other Dutch regions [22]. This study is embedded in an Academic Workplace, in which applied research is being carried out in close co-operation between scientists and professionals, facilitated by The Icare Foundation (home care organisation) and the Research Centre for the 
Table 1. Characteristics of health care professionals and parents taking part in focus groups and interviews
DOI: $10.1159 / 000345156$

Published online: October 26, 2012

Brink-Melis et al:: The Local Implementation of a Chronic Disease Management Model for Childhood Overweight and Obesity

\begin{tabular}{lll}
\hline Method & Discipline & $\begin{array}{l}\text { Number of } \\
\text { participants }\end{array}$ \\
\hline Focus group & physiotherapists & 6 \\
Focus group & dieticians & 4 \\
Focus group & YHC professionals & 6 \\
Focus group & pedagogues & 3 \\
Focus group & teachers & 5 \\
Interview 1 & pediatrician & 1 \\
Interview 1 & psychologist & 1 \\
Interview 1 & GP & 1 \\
Interview 1 & child care employee & 2 \\
Focus group & parents & 4 \\
Focus group & parents & 3 \\
\hline
\end{tabular}

Prevention of Overweight Zwolle (OPOZ) [23]. This study has been approved by the scientific committee of $\mathrm{EMGO}^{+}$at VU University and VU Medical Centre in Amsterdam. Data collection took place from June 2009 until January 2010.

\section{Focus Groups}

Focus groups were selected as the most appropriate method for investigating experiences, perceptions and expectations of both health care professionals and parents regarding the current health care for childhood overweight and obesity [20,24]. Focus groups produce insights due to the interaction in a group. The aim was to select homogeneous groups with at least 4 participants. Semi-structured interviews were planned when there were not enough participants to form a focus group. Informed consent was obtained from each participant.

\section{Health Care Professionals}

Health care professionals were selected by the project group on the basis of their potential role in identification or treatment of overweight or obese children. Recruitment took place with the help of the members of the project group. They approached their colleagues - working in the city of Zwolle - and invited them to participate in the focus groups. A total of 5 focus groups were held with each of the following disciplines: physiotherapists, dieticians, YHC professionals, pedagogues and teachers. Furthermore 4 semi-structured interviews were held with a paediatrician, a psychologist, a GP and with two child care employees. In total 29 health care professionals participated in this study. Characteristics are presented in table 1 .

\section{Parents}

Recruitment of parents of children (4-19 years) with overweight or obesity (based on self-report) who were residents of the city of Zwolle also took place with help of members of the project group. This process turned out to be very difficult. Reasons for parents not wanting to participate included lack of time and finding it hard to discuss the subject in a group. A total of 7 parents, all mothers, were willing to participate, forming 2 focus groups. Characteristics are presented in table 1.

\section{Data Collection}

Based on literature on integrated care and the development of a national management model for overweight and obesity, two road maps for the focus groups were developed, one for health care professionals and one for the parents [14, 25, 26]. For the interviews the same road map was used. Key themes regarding 
Table 2. Main key questions for focus groups and semi structured interviews with health care professionals

\begin{tabular}{|c|c|}
\hline Theme & Key questions \\
\hline Prevention & Can you say something about prevention activities related to weight in your work? \\
\hline Screening & $\begin{array}{l}\text { What is your role in screening? } \\
\text { Who determines if imminent overweight is indeed present? } \\
\text { Which care professionals have to discuss the problem of childhood overweight with } \\
\text { their parents? }\end{array}$ \\
\hline Treatment & $\begin{array}{l}\text { Can you say something about the possibilities for treatment? } \\
\text { Can you say something about the results of treatment? } \\
\text { Can you say something about the communication and cooperation between the } \\
\text { different care professionals? } \\
\text { What is necessary to improve the current situation? }\end{array}$ \\
\hline Relapse prevention & $\begin{array}{l}\text { What is your role in relapse prevention? } \\
\text { Which care professionals are involved? }\end{array}$ \\
\hline
\end{tabular}

integrated care such as co-operation and communication were formulated, and additional topics for discussions were listed. The questions focused on the perceptions and experiences of both health care professionals and parents on subjects such as prevention, screening, treatment and relapse prevention (table 2, table 3). Participants were asked to answer open-ended questions to elicit a wide range of responses. All sessions lasted between 1.5 and $2 \mathrm{~h}$ and were led by the same person (ERED). Observation during the focus groups took place by one of the members of the research group of this study. Participants' non-verbal behaviour and level of participation were observed and noted. All sessions were audio-recorded and transcribed verbatim.

\section{Data Preparation and Analysis}

Both the transcriptions of the sessions and the memos were used in the analysis. Transcripts were coded thematically, according to themes in the guidelines and themes that emerged in discussions, using the Atlas's software package (www.atlasti.com). Coding was done separately by two researchers (WB-M, ERED). Afterwards, they discussed differences and agreed upon final coding. These final codes were checked by a third researcher (TLSV) for consistency. Initial conclusions resulting from this analysis were checked with the health care professionals and parents (member checks); they agreed with these results. For further analysis, WB-M and ERED explored the codes and the memos of all sessions and discussed the most important findings. The researchers searched for similarities and differences throughout the sessions. The credibility of the interpretations was critically discussed by the research team [27].

\section{Results}

The focus groups provided information about local opportunities and barriers that should be taken into account to realise successful local implementation of a national chronic disease management model for childhood overweight and obesity. Both health care professionals and parents experience difficulties in finding the most appropriate care and difficulties in developing and maintaining a healthy life-style. 
Table 3. Main key questions for focus groups with parents

\begin{tabular}{ll}
\hline Theme & Key questions \\
\hline Prevention & $\begin{array}{l}\text { What sort of advice have you had to prevent overweight? } \\
\text { May health care professionals discuss the overweight problem of your child (with } \\
\text { you)? }\end{array}$ \\
\hline Screening & $\begin{array}{l}\text { How did you feel when a care provider discussed the overweight of your child? } \\
\text { What expectations do you have from health care professionals in relation to screening } \\
\text { and discussing the overweight of your child? }\end{array}$ \\
\hline Treatment & $\begin{array}{l}\text { What kind of advice/treatment did your child get with regards to overweight? } \\
\text { Can you say something about the communication and cooperation between the } \\
\text { different health care professionals? } \\
\text { What is necessary to improve the current situation? }\end{array}$ \\
\hline Relapse prevention & What expectations do you have about relapse prevention? \\
& Which health care professionals do you think have a role in relapse prevention?
\end{tabular}

\section{Finding the Most Appropriate Care}

Both professionals and parents agreed that at present, overweight and obese children often do not get the most appropriate care, indicating several barriers and also opportunities. The most important barriers are based on lack of awareness and difficulties to discuss and referral. The most important opportunities that were mentioned suggest more health checks and mutual cooperation between professionals.

\section{Lack of Awareness}

All health care professionals indicated that parents of overweight and obese children in general are not aware of the (over)weight and the risks of unhealthy life-styles. YHC professionals identified a lack in competences to apply appropriate motivational interviewing techniques. The perceived deficiency to apply appropriate motivational interviewing techniques and the lack of awareness among parents makes it difficult for YHC professionals to discuss overweight and related issues with parents.

According to health care professionals, parents with overweight children rarely ask for help with regard to tackling overweight of their child.

Physiotherapist: 'We put it like this in health care; do not provide help unless asked for. This group does not often ask for help. Treatment is nearly always bound to fail in such cases. If you want to do something useful, you will have to start asking the question: how can we get the parents to ask for help.'

\section{Discussing and Referring}

All health care professionals claimed difficulties to discuss the children's body weight with the parents, because it is not clear what appropriate follow-up strategies should be applied after diagnosis. Therefore, children are not referred or are referred too late. GPs do not always discuss the child's weight, because of a lack of possibilities for referrals and lack of time. The GP recognises this. Dieticians and physiotherapists experience that GPs do not refer patients to them at all or at a too late stage, leading to a large group not being treated. The paediatrician indicated that he could not yet clearly define his role in dealing with overweight and obese children, although he reported to discuss overweight and obesity on a regular basis. 
YHC: 'I usually see the negative side of the referral, the difficult path from YHC to the GP, for instance. The child is referred to a specialist, but then I do not see anything happen. GPs sometimes refer children to paediatricians and sometimes they don't, and at a certain moment, there's no more feedback anymore.'

Parents were surprised by the fact that health care professionals in general do not discuss their child's overweight or obesity. When parents are pro-actively seeking help for their child's overweight or obesity from professionals, they often feel that they are not being taken seriously.

Parent: 'If they tell you that your child is too fat, you think, well I know that myself. And then you think, so what? This is, in fact, naming the problem, but it doesn't help you in any way.'

Parent: 'With great difficulty we were finally referred to a dietician. I had to really speak up to accomplish something.'

Parents experience that GPs often refer rather randomly. They feel abandoned.

Parent: 'The doctor said: 'Perhaps your daughter should go to a good child physiotherapist. When I asked where I could find such a person, he told me he didn't know.'

\section{More Health Checks}

The YHC pointed out that especially between ages 5 and 11 years weight increases fast. It is during this period that there are only two health checks by YHC. This is experienced by YHC as a missed chance in detecting new cases of overweight. They argued in favour of more health checks during this period.

YHC: 'We should be more visible to the general public, which makes it possible for parents to approach us between regular health checks ... this used to be normal'.

\section{Mutual Cooperation}

Most health care professionals stated that, in general, the current treatments are mainly mono-disciplinary. The YHC focus group indicated that multidisciplinary co-operation takes place on a small scale and that this approach has shown positive results. This co-operation was mainly due to the fact that the various health care professionals worked in the same building.

\section{Long-Term Weight Management in Daily Practice}

Professionals and parents determine opportunities and barriers regarding long-term weight management of overweight and obese children in daily practice. The barriers are in the areas of motivation, appropriate advice, insufficient time for optimal treatment and maintaining and monitoring. The most important opportunity concerns fine tuning the expectations of the treatment between parents and professionals.

\section{Motivation}

Health care professionals mentioned that motivation of both parents and their children is important when starting a treatment and for adherence to treatment. Whereas young children are still dependent on their parents' motivation, dieticians indicated that parents' influence on children's life-style becomes smaller when children get older. The dieticians stated that parents also have persistent eating habits that are difficult to change. They found it difficult to motivate parents to change their own as well as their children's life-styles which is necessary for successful treatment. 
Brink-Melis et al.: The Local Implementation of a Chronic Disease Management Model for Childhood Overweight and Obesity

\section{Appropriate Advice}

The parents indicated that the advice and health recommendations given by health care professionals, especially by dieticians, did not fit activities in their daily life, making it difficult to maintain a healthy life-style. Their advices do not often take the parents' home environment into account and therefore do not match the expectations and needs of their children.

Parent: 'They may say he can only have one sandwich at lunch, but what if my child wants four?'

Insufficient Time for Optimal Treatment

Physiotherapists indicated that the effects of treatment are often temporary and, therefore, cannot reach the desired goals. Furthermore they indicated that parents often lack time during the day to take their children to treatment sessions. They are requesting treatment in the evenings more often because it fits their schedules better. The pedagogues acknowledged that parents have busy schedules and therefore cannot invest much time in their child's treatment.

Pedagogue: 'The parents are the stumbling block. We organised parent meetings, information sessions about nutrition, the psychological aspects, but the turnout was poor. It is really painful that many children are motivated and are willing to go to any trouble to be more active and eat different foods, but that parents have the tendency to curb the children: healthy nutrition is inconvenient now, or we can't do sport because we have to do something else now.'

\section{Maintaining and Monitoring}

Teachers claimed that it is very difficult for parents to maintain the newly acquired behaviour.

Teacher: 'I think that maintaining behaviour change is the most difficult thing for parents; we see that they start doing things differently, but they never persevere. They always relapse into their former behaviour, and it is extremely difficult to change that behaviour.'

The health care professionals evaluated their treatments with the parents and children on individual basis. They mentioned that there is hardly any monitoring and, if it happens, it lacks uniformity. Not one health care provider kept contact with the parents after a treatment was finished.

\section{Expectations of Treatment}

The parents indicated that their expectations of treatment differed from the health care professionals' expectations. As a result of these differences in expectations, parents and children often become disappointed about the treatment outcome. Pedagogues emphasised the importance of tailoring treatment to parents' and children's expectations.

Pedagogue: 'If the programme offered to the children is not the right one, they relapse into their old habits. If a child has a negative experience, he will not believe in the care that is provided and that is a very bad situation.'

The importance of realistic and feasible objectives was also mentioned by pedagogues as well as by the psychologist.

Psychologist: 'We must not think of putting them in a programme all the time, but we must listen to them, to what a patient is asking. We want so much, compulsive repairers as we are, while people actually do not want that at all.'

The parents found it important that the treatment complied with their child's wishes. Parents think that the responsibility for making choices for treatment lies with the parents themselves and, if possible, with the child.

Parent: 'We should be in charge, because we are the parents. It is different, of course, for each individual child, but I think that both the parents and the child should be in charge.' 
Brink-Melis et al.: The Local Implementation of a Chronic Disease Management Model for Childhood Overweight and Obesity

\section{Discussion}

The focus groups resulted in vivid discussions giving insights in the barriers and opportunities that were unknown before the research took place and could not have been detected without the focus groups. After thorough analysis of the focus groups, we were able to identify the most important barriers and opportunities. Further, at least as important as delivering important data, the focus groups and the feedback regarding the different focus groups led to an increased willingness to be involved in developing and implementing a multi-disciplinary action plan.

Both health care professionals as well as parents experience difficulties in finding the most appropriate care for the overweight and obese child. This is partly due to the fact that referral options are unclear for health care professionals and referrals occur on an occasional basis. When parents themselves do not ask for help with tackling their children's overweight, health care professionals find it difficult to discuss overweight and related issues. On the other hand, motivated parents do not always feel that they are taken seriously. Parents feel that the recommendations of health care professionals do not often match the expectations and needs of their children. When parents and children do receive appropriate care, it seems difficult for them to develop and maintain a healthy life-style. The child's environment, in which the unhealthy behaviour takes place, is not often taken into account by health care professionals. As a result, necessary changes in health behaviour are not being implemented in a sustainable manner, and parents, children and health care professionals become disappointed with the results.

This study clearly shows that the problem of obesity is multi-factorial and more than one various stakeholder should be involved in any approach towards obesity. This is also described in earlier studies [28, 29]. Hinchman et al. [30] suggested earlier that weight management should be more tailored to individuals' needs. Experiences from chronic disease management show that multi-disciplinary teams should be available to support the patient [31]. Such an integrated care approach should also be developed and implemented for childhood overweight and obesity to facilitate the current trend in Dutch health care to put more and more emphasis on parents' responsibility. A study by Nowicka and Flodmark [4] has shown promising results with a family-based approach regarding childhood obesity, taking into account the family home environment; they suggested that all interventions in paediatric obesity should include the family unit.

Mutual tuning and communication with parents is crucial and is confirmed in a study of Mikhailovich and Morrison [32]. Our findings that a good match between health care professionals and parents is necessary for successful prevention and treatment confirm findings by Schwartz et al., [33]. Pre-conditions such as sufficient checks, training in knowledge development and motivating interviewing techniques and institutional support will improve the care provided. Previous research also shows the need of these conditions [33-36].

Our strategy of recruiting the parents potentially may have resulted in response bias. As in similar studies, participants are likely to have a higher motivation level. We assume that children of less motivated parents even have more difficulty in receiving the most appropriate care. It has been reported that parents, in general, do underestimate their child's body weight status and that nearly half of the overweight children would be missed if relying on body weight figures reported by parents [37].

This study was performed with a small group of professionals and parents, but it was successful in sampling health care professionals of various disciplines and parents of overweight and obese children themselves. As a result, several perspectives could be compared and discussed. Overall the results gave insight into the way health care professionals and parents think, feel and act regarding integrated care for overweight and obesity. As a result of the focus 
groups, the different health care professionals have started agreements about treatment options and organised networks meetings. Also a digital overweight and obesity care programme is developed, describing actions, tasks and responsibilities regarding prevention and screening, diagnosis, treatment and relapse prevention, in order to provide essential information for professionals about integrated care for overweight and obese children.

\section{Conclusion}

Focus groups have provided essential information to create an emerging picture of professionals and parents having contradictory views and expectations about 'the others' role' and their notions on the capability to intervene and take action on children's weight problems. Without this qualitative research, issues concerning finding the most appropriate care and realising a long-term weight management in daily practice would not have become clear. Some examples of these issues are: lack of awareness, reluctance to discuss and refer, mutual co-operation, contradictory advice and expectations of treatment and lack of effective support strategies. Focus groups deliver important information on local issues that are important for the development and implementation of a childhood overweight management action plan. And, besides delivering necessary information, focus groups lead to an increased awareness and willingness to improve childhood overweight management in a local setting.

\section{Acknowledgement}

This study is part of a project aimed to achieve integrated care for children with overweight and obesity in the city of Zwolle. It is carried out by The Icare Foundation and the Research Centre for the Prevention of Overweight Zwolle (OPOZ). The infrastructure of this project consisted of a research group, a strategic group of the management of care organisations in Zwolle and a project group consisting of several care providers with different professions.

We would like to thank all the participants of the focus groups and our partners in this study: Foundation Icare and the local health organisations in the city Zwolle. We also would like to thank Margriet de Boer, project manager, for her contribution to the study. This research was funded by Zon Mw.

\section{Disclosure Statement}

The authors declare no conflict of interest.

\section{References}

1 van den Hurk K, van Dommelen P, van Buuren S, Verkerk PH, Hirasing RA: Prevalence of overweight and obesity in the Netherlands in 2003 compared to 1980 and 1997. Arch Disease Child 2007;92:992-995.

2 Schokker DF, Visscher TLS, Nooyens ACJ, van Baak MA, Seidell JC: Prevalence of overweight and obesity in the Netherlands. Obes Rev 2007;8:101-107.

3 WHO: Obesity: Preventing and managing the global epidemic. Report of a WHO consultation. World Health Organization Technical Report Series 2000, 894:i-xii,1-253.

- 4 Nowicka P, Flodmark CE: Family in pediatric obesity management: a literature review. Int J Pediatr Obes 2008;3:44-50.

5 Summerbell CD, Waters E, Edmunds LD, Kelly S, Brown T, Campbell KJ: Interventions for preventing obesity in children. Cochrane Database Syst Rev 2005;3:CD001871.

6 Dietz WH: Health Consequences of obesity in youth: childhood predictors of adult disease. Pediatrics 1998; 101:518-525.

7 Guo SS, Chumlea WC: Tracking of body mass index in children in relation to overweight in adulthood. Am J Clin Nutr 1999;70(suppl)145s-148s. 
Brink-Melis et al.: The Local Implementation of a Chronic Disease Management Model for Childhood Overweight and Obesity

8 Visscher TLS, Seidell JC: The public health impact of obesity. Annu Rev Public Health 2001;22:355-375.

$\checkmark 9$ Kremers SPJ, de Bruijn GJ, Visscher TLS, van Mechelen W, de Vries NK, Brug J: Environmental influences on energy balance-related behaviors: A dual- process view. Int J Behav Nutr Phys Activ 2006;3:9.

$\$ 10$ Swinburn B, Egger G, Raza F: Dissecting obesogenic environments: the development and application of a framework for identifying and prioritizing environmental interventions for obesity. Prev Med 1999;29: 563-570.

11 NICE Guideline: Obesity: The Prevention, Identification, Assessment and Management of Overweight and Obesity in Adults and Children. NICE Clinical guideline 43. London, National Institute for Health and Clinical Excellence, 2006.

12 Seidell JC, de Beer JJA, Kuijpers T: Guideline diagnosis and treatment of obesity in adults and children (in Dutch). Nederlands Tijdschrift Geneeskunde 2008;152:2071-2076.

13 Bodenheiner T: Interventions to improve chronic illness care: evaluating their effectiveness. Disease Manag 2003;6:63-71.

14 Drewes HW, Boom JHC, Graafmans WC, Struijs JN, Baan CA: Effectiveness of Disease Management (in Dutch). RIVM Rapport 260131001, Bilthoven, RIVM (National Institute for Public Health and the Environment), 2008.

15 Wagner EH, Austin BT, von Korff M: Organizing care for patients with chronic illness. Millbank Quarterly 1996;74:511-544.

16 Halberstadt J, Seidell JC, Hirasing RA, Renders CM, van Bolhuis AMP: Partnership Overweight Netherlands: the development of a chronic disease management model for overweight and obesity (in Dutch). Tijdschrift voor Gezondheidswetenschappen 2008;86:281-283.

17 CBO: Guideline Identification and Treatment of Obesity in Adults and Children (in Dutch). Utrecht, CBO, 2008.

18 Partnership Overweight the Netherlands: Chronic Disease Model for Obesity (in Dutch). Partnerschap Overgewicht Nederland, Amsterdam, PON, 2010.

-19 Renders CM, Halberstadt J, Frenkel CS, Rosenmöller P, Seidell JC, Hirasing RA: Tackling the problem of overweight and obesity: the Dutch approach. Obes Facts 2010;3:267-272.

20 Krueger RA, Casey MA: Focus Groups: A Practical Guide for Applied Research. Los Angeles, Sage, 2009.

-21 De Jong E, Schokker DF, Visscher TLS, Seidell JC, Renders CM: Behavioural and socio-demographic characteristics of Dutch neighbourhoods with high prevalence of childhood obesity. Int J Pediatr Obes 2011;6:298-305.

22 CBS (Centre for Statistics the Netherlands): 2010. www.cbs.nl.

-23 Derksen RE, Brink-Melis WJ, Westerman MJ, ten Dam JJM, Seidell JC, Visscher TLS: A local consensus process making use of focus groups to enhance the implementation of a national integrated health care standard on obesity care. Fam Pract 2012;29:i177-i184.

24 van Assema P, Mesters I, Kok GJ: Het focusgroep-interview: een stappenplan. Tijdschrift Sociale Gezondheidszorg 1992;70:431-437.

25 Donkers ECMM, Bras A, van Dingenen ECM: Integrated care with character (in Dutch). Medisch Contact 2008; 19:822-824.

26 Schrijvers G, Spreeuwenberg C, van der Laag H, Rutten G, Nabarro G, Schene A, Van der Linden B, Acampo M: Disease Management: The Dutch Context (in Dutch). Utrecht, Igitur, 2005.

27 Mays N, Pope C: Qualitative research: rigour \& qualitative research. BMJ 1995;311:109-112.

-28 Doak CM, Visscher TLS, Renders CM, Seidell JC: The prevention of overweight and obesity in children and adolescents: a review of interventions and programmes. Obes Rev 2006; 7:11-36.

29 Pagnini D, King L, Both S, Wilkenfeld R, Booth M: The weight of opinion on childhood obesity: recognizing complexity and supporting collaborative action. Int J Pediatr Obes 2009;4:233-241.

-30 Hinchman J, Beno L, Dennison D, Trowbridge F: Evaluation of a training to improve management of pedriatric overweight. J Contin Educ Health Prof 2005;25:259-267.

-31 Seals JP: Integrating the transtheoretical model into the management of overweight and obese adults. J Am Acad Nurse Pract 2007;19:63-71.

32 Mikhailovich K, Morrison P: Discussing childhood overweight and obesity with parents: a health communication dilemma. J Child Health Care 2007;11:311-322.

33 Schwartz RP, Hamre R, Dietz WH, Wasserman RC, Slora EJ, Myers EF, Sullivan S, Rockett H, Thoma KA, Dumitru G, Resnicow KA: Office-Bases motivational interviewing to prevent childhood obesity. Arch Pediatr Adolesc Med 2007;161:495-501.

-34 Story MT, Neumark-Stzainer DR, Sherwood NE, Holt K, Sofka D, Trowbridge FL Barlow SE: Management of child and adolescent obesity: attitudes, barriers, skills and training needs among health care professionals. Pediatrics 2002;110:210-214.

-35 Swinburn B. Obesity prevention in children and adolescents. Child Adolesc Psychiatr Clin N Am 2009;18: 209-223.

36 Boyle M, Lawrence S, Schwarte L, Samuels S, McCarthy J: Health care professionals' perceived role in changing environments to promote healthy eating and physical activity: baseline findings from health care professionals participating in the Healthy Eating, Active Communities Program. Pediatrics 2009;123(suppl 5):S293-S300.

-37 Scholtens S, Brunekreef B, Visscher TLS, Smit HA, Kerkhof M, Jongste JC, Gerritsen J, Wijga AH: Reported versus measured body weight and height of 4-year-old children and the prevalence of overweight. Eur J Pub Health 2007;17:369-374. 